\title{
Myocarditis in children presenting with acute febrile illness
}

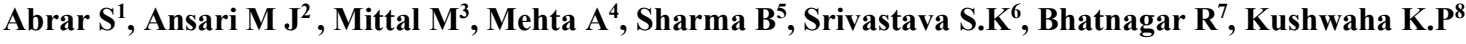 \\ ${ }^{1}$ Dr Shahla Abrar, Senior resident, Department of paediatrics, ${ }^{2}$ Dr Mohammed Junaid ansari, Lecturer, ${ }^{3}$ Dr Mahima \\ Mittal, Associate Professor, ${ }^{4}$ Dr Anita Mehta, Associate professor, ${ }^{5}$ Dr Bhoopendra Sharma, , Associate professor, ${ }^{6} \mathrm{Dr}$ \\ S.K. Srivastava, Associate professor, ${ }^{7}$ Dr Rachna Bhatnagar, Associate professor, ${ }^{8}$ Dr K.P. Kushwaha, Professor, \\ Department of paediatrics. All are affiliated with Department of Paediatrics, BRD medical college, Gorakhpur, UP India.
}

Address for correspondence: Dr Shahla Abrar, Email: shahlaabrar7@gmail.com

\begin{abstract}
Objective: Myocarditis is the inflammatory disease of myocardium. The objective of this study was to determine the prevalence of myocarditis in children presenting with acute febrile illness, the frequency of various presenting symptoms, and the accuracy of different investigations in the diagnosis and to know the outcome and etiological agents causing myocarditis. Methods: This prospective observational study was done in 125 children aged 1-15 years presenting with acute febrile illness. Patients were diagnosed as suspicious case of myocarditis on the basis of expanded criteria of myocarditis. Suspicious myocarditis patients were compared with those who did not have myocarditis in terms of clinical feature, investigation and outcome and were also investigated for etiology. Results: 43 patients were diagnosed as suspected myocarditis according to expanded criteria. Mean age was $6.1 \pm 3.4$ years and male: female ratio was 1.2:1. A significant association was present between patients with myocarditis and following signs and symptoms: chest pain, palpitation, dyspnea, swelling of body, pedal edema, abdominal tenderness, hepatomegaly and crepitations. Following investigations were significantly abnormal in patients with myocarditis: hypokalaemea, billirubin $>1.2 \mathrm{mg} / \mathrm{dl}$, mean AST and ALT, CPK-MB and BNP. Conclusions: Children with myocarditis present with symptoms that can be mistaken for other system involvement. When clinical suspicion of myocarditis exists, chest-X ray, cardiac enzymes and echocardiography are sufficient as screening tests. Many common causes of acute onset fever can cause myocaditis. Therefore its diagnosis is necessary for prompt treatment.
\end{abstract}

Key words- Myocarditis, Troponin I, Echocardiography, Children.

\section{Introduction}

Myocarditis is defined as an inflammatory disease of the myocardium [1]. It can be the result of viruses, bacteria (i.e. Streptococcus) and parasites (i.e. Trypanosoma cruzi), or drugs such as anthracyclines [1]. Viral infection is the common cause of myocarditis in United States [2-4]. Coxsackie B is the most well known cardiotoxic virus [1]. However, a number of other viruses have been implicated, including adenovirus, Epstein Barr virus, human herpes simplex virus type 6 , cytomegalovirus and parvovirus [2,5].

It accounts for nearly one half of all cases of dilated cardiomyopathy in children [6]. However, because children with myocarditis may be asymptomatic, the

Manuscript received: $20^{\text {th }}$ Feb 2016

Reviewed:5 March 2016

Author Corrected; $16^{\text {th }}$ March 2016

Accepted for Publication: $31^{\text {st }}$ March 2016 true incidence is unknown [7]. Clinical presentation of myocarditis may mimic other more common disorders such as asthma and gastroenteritis and so its diagnosis may become difficult [8-11]. Prompt diagnosis of myocarditis is necessary because the mortality rates for infants and children with myocarditis may be as high as $75 \%$ and $25 \%$, respectively, [12] and so early initiation of therapy is potentially beneficial [13]. Diagnosing myocarditis in children can be challenging. Not only can children have a wide range of nonspecific signs and symptoms, but depending on cognitive development, they may not be able to communicate their symptoms. Despite a variety of invasive and noninvasive studies, myocarditis is a presumptive diagnosis based on history and clinical features. $[7,10]$.

This study aimed to determine the prevalence of myocarditis in children presenting with fever of acute 
onset and to know the outcome in cases categorised as suspected Myocarditis in terms of mortality, duration of ICU stay and to know the etiology.

\section{Methodology}

This is a cohort study in which all children aged 1-15 years who presented with the fever of acute onset (less than 15 days in duration) in Pediatrics ward at our institute over a period of one year on alternate days in a week were enrolled. Children with known cardiac lesions, either congenital or acquired, and presenting with heart failure were excluded. Detailed history and clinical examination were done and recorded.

Routine laboratorial test - complete blood count, erythrocyte sedimentation rate (ESR), C-reactive protein (CRP) were done in all children. Chest X-ray, cardiac enzymes: Troponin I, BNP and CPK-MB (The Alere Triage ${ }^{\circledR}$ Cardio3 Panel) were done at admission. Electrocardiogram; and detailed echocardiography including M-mode, 2-dimensional, and colour doppler echocardiography with color-coding character was done in all patients. Echocardiograms were performed in the left lateral position, echocardiographic equipment (Toshiba SSA 380 Power-Vision, Tokyo, Japan). We followed standard measurements made from $\mathrm{M}$ mode echocardiograms [14, 15]. Percentile charts (3rd, 10th, 25th, 50th, 75th, 90th, and 97th centiles) were constructed for each measurement in relation to body surface area [16].

Patients were diagnosed to have myocarditis on the basis of expanded criteria for diagnosing myocarditis [17].

Expanded criteria for diagnosis of myocarditis.

Suspicious for myocarditis $=2$ positive categories, Compatible with myocarditis $=3$ positive categories, High probability of being myocarditis $=$ all 4 categories positive.

Any matching feature in category $=$ positive for category.

Category I: clinical symptoms

Clinical heart failure, Fever, Viral prodrome, Fatigue, Dyspnea on exertion, Chest pain, Palpitation, Presyncope or syncope

Category II: Evidence of Cardiac Structural or Functional Perturbation in the absence of Regional Coronary Ischemia.

1. Echocardiography evidence
Regional wall motion abnormalities

Cardiac dilation

Regional cardiac hypertrophy

2. Troponin release High sensitivity $(>0.1 \mathrm{ng} / \mathrm{mL})$

3. Positive indium In 111 antimyosin scintigraphy .

Category III: Cardiac Magnetic Resonance Imaging 1. Increased myocardial $\mathrm{T} 2$ signal on inversion recovery sequence.

2. Delayed contrast enhancement after gadoliniumdiethylenetriamine penta-acetic acid infusion

Category IV: Myocardial biopsy.

1. Pathology findings compatible with Dalla's criteria

2. Presence of viral genome by polymerase in situ hybridization.

Suspicious myocarditis patients were compared with the children who did not have myocarditis with assessment of clinical feature, investigation and outcome. Assessment of the need for mechanical ventilation [MV]); assessment of cardiac decompensation and need for cardiac support (inotropes, decongestive therapy or antifailure drugs) was done.

All patients of AFI diagnosed as suspected myocarditis on the basis of clinical features, troponin I and Echocardiography had a full work up for the cause of fever that included three smears for malarial parasites, RDT for malarial parasite (MERISCREEN malaria $\mathrm{Pf} / \mathrm{Pv} \mathrm{Ab}$ ) serology for dengue (standard diagnostic USA), Weil felix test for Rickettsial infection, enteric fever (Typhi check standard diagnostic USA), Measles and mumps was tested in patients serum (Siemens antimeasles virus ELISA kit); blood, urine, and sputum or endotracheal cultures if required.

\section{Statistical analysis}

Mean and standard deviations were calculated for all continuous variables. Student t-test was used to determine if the difference between the means was statistically significant. A Fisher exact $\mathrm{p}$ value $<0.05$ were regarded as significant

\section{Results}

This study comprised 150 children presenting with fever of acute onset admitted to the PICU in B. R. D. medical college. Out of this 25 patients were excluded: 14 patients were known cases of congenital heart disease (cyanotic or acyanotic), 7 were of Rheumatic heart disease, 4 were diagnosed cases of dialated 
cardiomyopathy. Out of 125 children, 43 (34.4\%) patients were diagnosed as suspicious myocarditis according to expanded criteria for myocarditis based on clinical features, troponin I and echocardiography.

Patient's characteristics: Mean age for those diagnosed myocarditis was $6.1 \pm 3.4$ years and male: female ratio was $1.2: 1$. Duration of fever was $6.1 \pm 2.85$ days and $46.5 \%(n=20)$ of children were malnourished.
Clinical features: A significant association was present between patients with myocarditis and following signs and symptoms: chest pain $(39.5 \%, \mathrm{n}=17)$, palpitation $(65.1 \%, \mathrm{n}=28)$, dyspnea $(83.7 \%, \mathrm{n}=36)$, swelling of body $(62,79 \%, n=27)$, tachycardia $(81.39 \%, n=35)$, pedal edema (30.2\%, $\mathrm{n}=13)$, abdominal tenderness $(60.4 \%, \mathrm{n}=26)$, hepatomegaly $(81.4 \%, \mathrm{n}=35)$ and crepitations $(46.5 \%, \mathrm{n}=20)$. (Table 2 )

Table1: Patients Characteristics

\begin{tabular}{llll}
\hline Parameters & $\begin{array}{l}\text { Myocarditis } \\
\text { yes, } \mathbf{n}=\mathbf{4 3}\end{array}$ & $\mathbf{n o ,} \mathbf{n = 8 2}$ & p value \\
\hline age, mean (SD) & $6.1(3.42)$ & $5.59(3.38)$ & 0.4263 \\
M:F & $1.2: 1$ & $1.6: 1$ & 0.4605 \\
fever (duration) & $6.1(2.85)$ & $6.5(2.88)$ & 0.7079 \\
malnutrition (<-3SD) & $20(46.5)^{*}$ & $35(42.68)^{*}$ & \\
\hline
\end{tabular}

Table 2: Clinical features in patients of myocarditis

\begin{tabular}{|c|c|c|c|}
\hline \multirow[t]{2}{*}{ Parameters } & \multicolumn{2}{|l|}{ Myocarditis } & \multirow[t]{2}{*}{ p value } \\
\hline & Yes, $n=43(\%)$ & no, $\mathrm{n}=82(\%)$ & \\
\hline \multicolumn{4}{|l|}{ Symptoms } \\
\hline Headache & $29(67.44)$ & $53(64.63)$ & 0.8439 \\
\hline Abdominal pain & $30(69.76$ & $65(79.26)$ & 0.2734 \\
\hline Arthralgia & $11(25.58)$ & $15(18.29)$ & 0.3607 \\
\hline Chest pain & $17(39.53)$ & $9(10.9)$ & 0.0004 \\
\hline Palpitation & $28(65.11)$ & $10(12.19)$ & 0.0001 \\
\hline Dyspnea & $36(83.7)$ & $22(26.82)$ & 0.0001 \\
\hline Swelling of body & $27(62.79)$ & $35(42.68)$ & 0.0392 \\
\hline \multicolumn{4}{|l|}{ Signs } \\
\hline Pedal edema & $13(30.2)$ & $11(13.41)$ & 0.0315 \\
\hline Facial puffiness & $26(60.4)$ & $35(42.68)$ & 0.0633 \\
\hline Rash & $6(13.9)$ & $16(19.51)$ & 0.6216 \\
\hline Abdominal tenderness & $26(60.4)$ & $18(21.9)$ & 0.0001 \\
\hline Hepatomegaly & $35(81.39)$ & $50(60.9)$ & 0.0261 \\
\hline Splenomegaly & $22(51.1)$ & $29(35.36)$ & 0.1249 \\
\hline Crepitations & $20(46.5)$ & $14(17.07)$ & 0.0007 \\
\hline
\end{tabular}


Table 3: Investigations in patients of myocarditis

\begin{tabular}{|c|c|c|c|}
\hline \multirow[t]{2}{*}{ Parameters } & \multicolumn{2}{|l|}{ Myocarditis } & \multirow[t]{2}{*}{ p value } \\
\hline & Yes , $n=43(\%)$ & no, $n=82(\%)$ & \\
\hline Hemoglobin $(<10 \mathrm{~g} / \mathrm{dl})$ & $20(46.5)$ & $48(58)$ & 0.257 \\
\hline Total leucocyte count $(>15000 /$ microliter $)$ & $7(16.2)$ & $15(18.2)$ & 1 \\
\hline Platelets $<1$ lakh $/$ microliter & $24(55.8)$ & $32(39.02)$ & 0.0894 \\
\hline Platelets $<50000 /$ microliter & $10(23.2)$ & $21(25.6)$ & 0.8304 \\
\hline serum $\mathrm{Na}(<120 \mathrm{meq} / \mathrm{dl})$ & $4(9.3)$ & $5(6.09)$ & 0.4929 \\
\hline serum $\mathrm{Na}(>150 \mathrm{meq} / \mathrm{dl})$ & $1(2.3)$ & 0 & 0.344 \\
\hline Serum $\mathrm{K}<2.5 \mathrm{meq} / \mathrm{dl}$ & $4(9.3)$ & $1(1.2)$ & 0.0473 \\
\hline Serum $\mathrm{K}>5 \mathrm{meq} / \mathrm{dl}$ & $3(6.9)$ & $9(10.9)$ & 0.5426 \\
\hline Azotemia $($ Urea $>40 \mathrm{mg} / \mathrm{dl})$ & $20(46.5)$ & $27(32.9)$ & 0.174 \\
\hline Creatinine $\mathrm{mg} / \mathrm{dl}$ & $17(39.5)$ & $21(25.6)$ & 0.1513 \\
\hline $\mathrm{AST}>40 \mathrm{IU} / \mathrm{dl}$ & $38(88.37)$ & $65(79.2)$ & 0.2285 \\
\hline $\mathrm{ALT}>40 \mathrm{IU} / \mathrm{dl}$ & $38(88.37)$ & $67(79.2)$ & 0.4439 \\
\hline $\mathrm{AST}$, mean $(\mathrm{SD})$ & $138.71(86.32)$ & $95.4(88.48)$ & 0.0099 \\
\hline ALT, mean (SD) & $134.42(91.22)$ & $92.55(91.04)$ & 0.0161 \\
\hline Serum Billirubin $(>1.2 \mathrm{mg} / \mathrm{dl})$ & $18(41.86)$ & $13(15.85)$ & 0.0021 \\
\hline CPK-MB $>-=4.3 \mathrm{ng} / \mathrm{dl}$ & $25(58.13)$ & $26(31.7)$ & 0.007 \\
\hline $\mathrm{BNP}(>=100)$ & $24(55.81)$ & $23(28)$ & 0.0034 \\
\hline
\end{tabular}

AST - aspartate aminitransferase, ALT - alanine aminotransferase, CK-MB - creatinine phosphokinase -MB, BNP brain natriuretic polypeptide

Table 4: Chest X-RAY, ECG and echocardiography in patients of myocarditis

\begin{tabular}{|c|c|c|c|}
\hline & \multicolumn{2}{|l|}{ Myocarditis } & \multirow[t]{2}{*}{ p value } \\
\hline & Yes, $n=43(\%)$ & No, $n=82(\%)$ & \\
\hline \multicolumn{4}{|l|}{ Chest X-Ray } \\
\hline cardiomegaly (CT ratio $>50)$ & $18(41.8)$ & $15(18.29)$ & 0.0059 \\
\hline pulmonary congestion & $33(76.7)$ & $36(43.9)$ & 0.0006 \\
\hline \multicolumn{4}{|l|}{ Electrocardiography } \\
\hline low voltage complexes & $22(51.1)$ & $8(9.7)$ & 0.0001 \\
\hline ST elevation & $4(9.3)$ & $1(1.2)$ & 0.0473 \\
\hline $\mathrm{T}$ wave changes & $11(25.5)$ & $13(15.8)$ & 0.2334 \\
\hline AV conduction defects & $4(9.3)$ & $3(3.6)$ & 0.2315 \\
\hline ventricular arrhythmia & $4(9.3)$ & 0 & 0.0473 \\
\hline \multicolumn{4}{|l|}{ Echocardiography } \\
\hline ejection fraction $<50$ & $17(39.5)$ & - & \\
\hline regional wall motion abnormalities & $17(39.5)$ & - & \\
\hline pericardial effusion & $11(25.5)$ & - & \\
\hline functional regurgitation & $6(13.9)$ & - & \\
\hline cardiac dialatation & $3(6.9)$ & - & \\
\hline regional cardiac hypertrophy & $2(4.6)$ & - & \\
\hline
\end{tabular}


Table 5: etiological agents in patients of myocarditis

\begin{tabular}{ll}
\hline etiological agent & Number of patients n(\%) \\
\hline Salmonella typhi & $7(16.27)$ \\
IgM dengue & $5(11.62)$ \\
RDT for MP & $6(13.95)$ \\
Measles antibody & $2(4.65)$ \\
Rickettsial (Weil Felix test) & $1(2.3)$ \\
blood culture positive (staph epidermides) & $2(4.65)$ \\
blood culture positive (streptococcus sp.) & $1(2.3)$ \\
blood culture positive (gram negative cocci) & $2(4.65)$ \\
not known & $17(39.53)$ \\
\hline Total & $\mathbf{4 3 ( 1 0 0 )}$ \\
\hline
\end{tabular}

Table 6: outcome in patients of Myocarditis

\begin{tabular}{lllll}
\hline Parameters & Myocarditis & & p value & Odds \\
& Yes & no & & \\
\hline Mortality & $9(20.9)$ & $4(4.8)$ & 0.016 & 5.1 \\
duration of ICU stay & $5.48(3.9)$ & $4.4(4.09)$ & 0.1568 & - \\
need for ventilation & $7(16.2)$ & $6(7.3)$ & 0.1334 & 2.5 \\
need for ionotropes & $24(55.8)$ & $39(47.5)$ & 0.4525 & 1.3 \\
\hline
\end{tabular}

Investigations: Following investigations were significantly abnormal in patients with myocarditis: hypokalaemea (serum $\mathrm{K}<2.5 \mathrm{meq} / \mathrm{dl}$ ), Serum billirubin $>1.2 \mathrm{mg} / \mathrm{dl}$, CPK-MB and BNP. (Table 3) AST (aspartate aminotransferase) and ALT (alanine aminotransferase) were increased in all patients, but their mean value was significantly more in children with myocarditis $(\mathrm{p}<0.05)$. On CXR, cardiomegaly $(41.8 \%, \mathrm{n}=18)$ and pulmonary congestion $(76.7 \%, \mathrm{n}=33)$ and on ECG, low voltage complexes $(51.1 \%, \mathrm{n}=22)$, ST elevation $(9.3 \%, \mathrm{n}=4)$ and ventricular arrhythmia $(9.3 \%, \mathrm{n}=4)$ were significantly present in myocarditis patients. (Table 4) Common echocardiographic findings in patients with myocarditis are ejection fraction $<50 \%(39.5 \%)$, regional wall motion abnormalities $(39.5 \%)$, pericardial effusion $(25.5 \%)$, cardiac dialatation $(6.9 \%)$ and regional cardiac hypertrophy $(4.6 \%)$. (Table 4$)$

Etiology: Regarding the etiological agents that were causing myocarditis IgM for dengue was positive in 5, patients, RDT for MP was positive in 6, IgM antibodies for typhoid was positive in 7 children, measles in 2, blood culture was positive for streptococcus species in 1, staphylococcal epidermidis in 2, and gram negative cocci in 2 cases. In 17 $(39.53 \%)$ of cases no etiology was found. Weil felix test was positive in one child. (Table 5)

Outcome: Mortality was more in patients with myocarditis. $(20.9 \%, \mathrm{p}=0.016)$. There was no difference in duration of ICU stay, need for ionotropes and ventilation. (Table 6) But patients with myocarditis had almost 2.5 fold increase odds of minute ventilation and 1.3 folds increase odds of ionotrope support when compared with patients not having myocarditis. 


\section{Discussion}

While pediatric myocarditis presents with significant morbidity and mortality, data on prevalence are limited, and the diagnosis remain challenging. In our study, it was found that the prevalence of myocarditis was $34.4 \%$ in children presenting with acute onset of fever. In a similar study done in Cairo University, prevalence was $25.3 \%$ [18]. Mean age of presentation of myocarditis patients was $6.1 \pm 3.4$ years. Soongswang et al. [19] detected acute myocarditis among patients with mean age $5.4 \pm 5.1$ years. Male predominance is noted in this study may be due to cardioprotective effects of hormones in women [20]. Signs and symptoms of heart failure; tachycardia, chest pain, palpitation, swelling of body, dyspnea, pedal edema and hepatomegaly were common. Abdominal pain was also significantly found. Gastrointestinal symptoms like abdominal pain and vomiting are common and myocarditis can be confused easily with gastroenteritis $[9,10]$. However, the evidence to date has been in the form of case reports [21]. The literature does contain several reports of adult myocarditis associated with Campylobacter, [11] Shigella [11]. Myocarditis presenting with abdominal pain and vomiting in the absence of proven acute gastrointestinal infection is probably underreported. The symptom complex may be attributable to reduced gastrointestinal tract perfusion secondary to myocardial dysfunction. Local vasoconstriction and gut ischemia can result from activation of sympathetic system, after development of hypotention $[9,22]$. In our study, $81.4 \%$ of patients with Myocarditis had hepatomegaly and $46.5 \%$ had crepitation on respiratory examination. Durani et al. [23] found $50 \%$ of the patients with myocarditis had hepatomegaly and $34 \%$ had abnormal lung examination in his study. We found that AST and ALT were increased in $88.37 \%$ of the patients but their increase was not significant. However, their mean value was more in patients of myocarditis $(p<0.05)$. Earlier Freedman et al. [24] found that the most sensitive marker for myocarditis was an elevated AST, which was elevated in $85 \%$ of cases of myocarditis. Elevations of liver enzyme levels may be due to passive hepatic congestion [25]. Increase in serum billirubin $(>1.2 \mathrm{mg} / \mathrm{dl})$ was also significantly associated with patients of myocarditis in this study.

Cardiac troponins used as the first investigations for diagnosing suspicious myocarditis and was done in all patients enrolled for the study. It was observed in this study that, $\mathrm{CPK}-\mathrm{MB}$ and $\mathrm{BNP}$ were significantly raised in patients of myocarditis. Elevations of CK and CPKMB have been previously reported in myocarditis [26]. In our series, cardiomegaly and pulmonary congestion was significantly present in myocarditis patients. Although they are recommended routinely for the evaluation of myocarditis [7-10], few data exist on the sensitivity of chest radiographs. [27] On electrocardiography, low voltage complexes, ST elevation and ventricular arrhythmia was significantly found in our study. It was stated previously that the 2 most important ECG features are low-voltage QRS complexes and flat or inverted $\mathrm{T}$ waves in the standard and/or precordial leads [28]. $\mathrm{T}$ wave changes were present in $25 \%$ of our patients of myocarditis. Durani et al. [23] showed that in $98 \%$ of cases of pediatric myocarditis, the echocardiography would be abnormal, with segmental wall motion abnormalities being the most common findings (hypokinesia, akinesia and dyskinesia). Similarly, in our study regional wall motion abnormality was common echocardiographic finding. Pericardial effusion was present in $25.5 \%$ of patients of myocarditis. Although both acute myocarditis and acute pericarditis, usually have a viral cause, they are not always associated and the clinical emphasis is usually on one or the other [29]. We have found malaria, typhoid, dengue, measles, reckettsial infection and bacteraemia as the cause of myocarditis in our study. Several previous studies and case reports had shown the role of these diseases in causing myocarditis [30-36] we had $18 \%$ of cases in which no etiology could be found. A report by klugman et al, [37] found that $82 \%$ of pediatric cases studied were considered idiopathic. One child having eschar was positive for weil felix test. The poor sensitivity of the Weil felix test are now well demonstrated but a good correlation between the results of this test and IgM antibodies by an immunoflourescence assay is often demonstrated [38]. We also could not do the test for enteroviruses in our study. However previous studies had demonstrated prevalence of enteroviral infection in this region. [39] Regarding the support offered to myocarditis cases, $16.2 \%$ required ventillatory support, while, in the study by Klugman et al., $37.5 \%$ required minute ventilation. [37] Moreover, inotropic support was offered to $55.8 \%$ of the suspicious myocarditis cases in our study, compared to around $35 \%$ in Klugman et al study [37]. The mortality rate among myocarditis cases was $20.9 \%$ and was significantly more than other patients of acute febrile illness. Previous reports ranged from 13 to $38 \%$. $[19,40]$. 


\section{Conclusion}

This study demonstrates that pediatric myocarditis is common in children with acute febrile illnesses in this region, which highlights the need for clinicians to maintain a high index of suspiion for myocarditis even in the absence of clinical findings of congestive heart failure. Patients presented primarily with respiratory and cardiac complaints. Gastrointestinal complaints were also common in patients of myocarditis. When adequate clinical suspicion exists, screening tests should include cardiac markers, chest radiographs and ECGs. Evidence of elevated liver enzyme levels should also raise additional concern regarding myocarditis in the appropriate clinical scenario. We have found malaria, typhoid, dengue, measles, reckettsial infection and bacteraemia as the cause of myocarditis in our study in this region.

\section{Funding: None}

Conflicts of Interest: None

\section{References}

1. Sparrow PJ, Merchant N, Provost YL, Doyle DJ, Nguyen ET, Paul NS. CT and MR imaging findings in patients with acquired heart disease at risk for sudden cardiac death. Radiographics 2009 MayJune; 29(3):805-823. doi: 10.1148/rg.293085715.

2. Kearney MT, Cotton JM, Richardson PJ, Shah AM. Viral myocarditis and dilated cardiomyopathy: mechanisms, manifestations, and management. Postgrad Med J 2001 Jan; 77(903):4-10.

3. Vashist S, Singh GK. Acute myocarditis in children: current concepts and management. Curr Treat Options Cardiovasc Med. 2009 Oct;11(5):383-91.

4. Robinson J, Hartling L, Vandermeer B, Crumley E, Klassen TP. Intravenous immunoglobulin for presumed viral myocarditis in children and adults. Cochrane Database Syst Rev. 2005 Jan 25;(1):CD004370.

5. Kuhl U, Pauschinger M, Bock T, Klingel K, Schwimmbeck CP, Seeberg B, et al. Parvovirus B19 infection mimicking acute myocardial infarction. Circulation 2003 Aug 26;108(8):945-50.

6. Towbin JA, Lowe AM, Colan SD, Sleeper LA, Orav EJ, Clunie S, et al. Incidence, causes, and outcomes of dilated cardiomyopathy in children. JAMA. 2006 Oct 18;296(15):1867-1876.

7. Feldman AM, McNamara D. Medical progress: Myocarditis. N Engl J Med. 2000 Nov 9;343(19):13881398.
8. Chang YJ, Chao HC, Hsia SH, Yan DC. Myocarditis presenting as gastritis in children. Pediatr Emerg Care. 2006 June;22(6):439-440.

9. Bohn D, Benson L. Diagnosis and management of pediatric myocarditis. Paediatr Drugs. 2002;4(3):171181.

10. Levi D, Alejos J. Diagnosis and treatment of pediatric viral myocarditis. Curr Opin Cardiol. 2001 March;16(2):77-83.

11. Kotilainen $\mathrm{P}$, Lehtopolku M, Hakanen AJ. Myopericarditis in a patient with Campylobacter enteritis: a case report and literature review. Scand J Infect Dis. 2006;38(6-7):549-552.

12. Dancea AB. Myocarditis in infants and children: a review for the paediatrician. J Paediatr Child Health. 2001;343:1388-1398.

13. Drucker NA, Colan SD, Lewis AB, Beiser AS, Wessel DL, Takahashi M, Baker AL, et al. Globulin treatment of acute myocarditis in the pediatric population. Circulation. 1994 Jan;89(1):252-257.

14. Roeland J, Gibson DG. Recommendations for standardization of measurements from M-mode echocardiograms. Eur Heart J 1980 Oct;1(5):375-8.

15. Sahn DJ, DeMaria A, Kisslo J, Weyman A. Recommendations regarding quantitation in M-mode echocardiography: results of a survey of echocardiographic measurements. Circulation 1978 Dec;58(6):1072-83.

16. C Kampmann, C M Wiethoff, A Wenzel, G Stolz,M Betancor, C-F Wippermann, R-G Huth, P Habermehl,M Knuf, T Emschermann, H Stopfkuchen. Normal values of $\mathrm{M}$ mode echocardiographic measurements of more than 2000 healthy infants and children in central Europe Heart 2000 June;83(6):667-672.

17. Braunwald's heart desease, $8^{\text {th }}$ ed. Philadelphia, PA:Saunders Elsevier;2007:1775-1791.

18. Rady HI, Zekri H. Prevalence of myocarditis in pediatric intensive care unit cases presenting with other system involvement. J Pediatr (Rio J). 2015 JanFeb;91(1):93-7. doi: 10.1016/j.jped.2014.05.011.

19. Soongswang J, Durongpisitkul K, Nana A, Laohaprasittiporn D, Kangkagate C, Punlee K, et al. Cardiac troponin $\mathrm{T}$ : a marker in the diagnosis of acute myocarditis in children. Pediatr Cardiol. 2005 JanFeb;26(1):45-9. 
20. Schwartz J, Sartini D, Huber S. Myocarditis susceptibility in female mice depends upon ovarian cycle phase at infection. Virology 2004 Dec $5 ; 330(1): 16-23$.

21. Chang YJ, Chao HC, Hsia SH, Yan DC. Myocarditis presenting as gastritis in children. Pediatr Emerg Care. 2006 Jun;22(6):439-40.

22. Trompeter M, Brazda T, Remy CT, Vestring T, Reimer P. Non-occlusive mesenteric ischemia: etiology, diagnosis, and interventional therapy. Eur Radiol. 2002 May;12(5):1179-87.

23. Durani Y, Egan M, Baffa J, Selbst SM, Nager AL. Pediatric myocarditis: presenting clinical characteristics. Am J Emerg Med 2009 Oct;27(8):9427. doi: 10.1016/j.ajem.2008.07.032.

24. Freedman SB, Haladyn JK, Floh A, Kirsh JA, Taylor. Pediatric myocarditis: emergency department clinical findings and diagnostic evaluation. Pediatrics 2007 Dec;120(6):1278-85.

25. Naschitz JE, Slobodin G, Lewis RJ, Zuckerman E, Yeshurun D. Heart diseases affecting the liver and liver diseases affecting the heart. Am Heart J. Naschitz JE, Slobodin G, Lewis RJ, Zuckerman E, Yeshurun D. Heart diseases affecting the liver and liver diseases affecting the heart. Am Heart J. 2000;140:111-120.

26. Chemnitz G, Schmidt E, Schmidt FW, Gahl K, Lobers $\mathrm{J}$. The creatinine kinase MB isoenzyme in heart failure and inflammation. In:Lang $\mathrm{H}$, ed. Creatinine kinase Isoenzyme. Berlin, Germany: SpringerVerlag..1981:165-169.

27. Drucker NA, Newburger JW. Viral myocarditis: diagnosis and management. Adv Pediatr. 1997;44:141171.

28. Keith JD, Rowe RD, Vlad P, eds. Heart Disease in Infancy and Childhood. New York, NY: Macmillan; 1978.

29. Oakley CM. Myocarditis, pericarditis and other pericardial diseases. Heart. 2000 Oct;84(4):449-54.

30. Herrera JM. Cardiac lesion in vivax malaria. Study of a case with coronary and myocardial damage. Arch Inst Cardiol Mex. 1960 Jan-Feb;30:26-36.
31. Khattak AL, Ali W, Samore NA, Idris M, Khan MN, Pasha W. Complicated plasmodium falciparum malaria initially presenting as myocardites. J Ayub Med Coll Abbottabad. 2014 Jul-Sep;26(3):413-5.

32. Kabra, S.K., Juneja, R., Madhulika, Jain, Y., Singhal, T., Dar, L. et a. , Myocardial dysfunction in children with dengue haemorrhagic fever. Natl Med J India. 1998 Mar-Apr;11(2):59-61.

33. C.R. Burt, J.C. Proudfoot, M. Roberts, R.H. Horowitz. Fatal myocarditis secondary to Salmonella septicemia in a young adult J Emerg Med. 1990 MayJun;8(3):295-7.

34. Frustaci A, Abdulla AK, Caldarulo M, Buffon A. Fatal measles myocarditis. Cardiologia. 1990 Apr;35(4):347-9.

35. Haddad F, Berry G, Doyle R, Martineau P, Leung T, Racine N. Active Bacterial Myocarditis: A Case Report and Review of the Literature. J Heart Lung Transplant. 2007 Jul;26(7):745-9.

36. Salvi A, Della Gazia E, Silvestri F, Camerini F. Acute rickettsial myocarditis and advanced atrioventricular block: diagnosis and treatment aided by endomyocardial biopsy. Int Cardiol. 1985 Apr;7(4):405-9.

37. Klugman D, Berger JT, Sable CA, He J, Khandelwal SG, Slonim AD. Pediatric patients hospitalized with myocarditis: a multi- institutional analysis. Pediatr Cardiol. 2010 Feb;31(2):222-8. ssdoi: 10.1007/s00246-009-9589-9.

38. La Scola B, Raoult D. Laboratory diagnosis of Rickettsioses: Current approach to diagnosis of old and new rickettsial Diseases. J Clin Microbiol 1997 Nov;35(11):2715-27.

39. Gajanan N. Sapkal, Vijay P. Bondre, Pradip V. Fulmali, Pooja Patil, V, Gopalkrishna, Vipul Dadhania, et al. Enteroviruses in Patients with Acute Encephalitis, Uttar Pradesh, India. Emerg Infect Dis. 2009 Feb; 15(2): 295-298.

40. Fuse K, Kodama M, Okura Y, Ito M, Hirono S, Kato K, et al. Predictors of disease course in patients with acute myocarditis. Circulation. 2000 Dec $5 ; 102(23): 2829-35$

\section{How to cite this article?}

Abrar S, Ansari M J, Mittal M, Mehta A, Sharma B, Srivastava S.K, Bhatnagar R, Kushwaha K.P. Myocarditis in children presenting with acute febrile illness. Int J Pediatr Res 2016;3(3):188-195. doi:10.17511/ijpr.2016.103.09. 